\title{
The Implicit Power Motive and Adolescents' Salivary Cortisol Responses to Acute Psychosocial Stress and Exercise in School
}

\author{
Mirko Wegner ${ }^{*}$, , Julia Schüler ${ }^{1}$, Katharina S. Scheuermann ${ }^{2}$, Sergio Machado ${ }^{3,4}$ and Henning Budde ${ }^{5,6}$ \\ ${ }^{1}$ University of Bern, Institute of Sport Science, Switzerland \\ ${ }^{2}$ Humboldt-Universität zu Berlin, Germany \\ ${ }^{3}$ Laboratory of Panic and Respiration, Institute de Psychiatry, Federal University of Rio de Janeiro, \\ Rio de Janeiro, Brazil \\ ${ }^{4}$ Physical Activity Neuroscience, Physical Activity Sciences Post-Graduate Program, Salgado Oliveira \\ University, Niterói, Brazil. \\ ${ }^{5}$ Medical School Hamburg, Faculty of Human Sciences, Germany \\ ${ }^{6}$ Reykjavik University, School of Science and Engineering, Department of Sport Science, Iceland
}

\begin{abstract}
In the present study we examined the moderating effect of the power motive on salivary cortisol responses to acute psychosocial stress and exercise in adolescents. Fifty-seven high school students aged $M=14.8$ years participated in the study. The Operant Motive Test was applied to measure the implicit power motive and the Personality Research Form was used to measure the explicit power motive. Salivary cortisol levels were assessed before and after the stress stimuli. Participants were randomly assigned to three experimental groups. An exercise group ran 15 minutes at a defined heart rate of $65-75 \% \mathrm{HR}_{\max }$. A psychosocial stress group worked on a standard intelligence test for the same amount of time under the assumption, that their test scores will be made public in class after the test. The control group participated in a regular class session. The implicit power motive was significantly associated with increased cortisol levels in the psychosocial stress group. The explicit power motive was not associated with cortisol responses. Findings suggest that the implicit power motive moderates the cortisol responses to acute stress in an adolescent age group with higher responses to psychosocial stress in comparison to exercise or control conditions.
\end{abstract}

Keywords: Implicit power motive, Cortisol, Psychosocial stress, Exercise, Adolescents

\section{INTRODUCTION}

Exercise and socio-evaluative situations are stressors that can be found in a typical day of school. Both, acute exercise [1, $2]$ and acute socio-evaluative stress $[3,4]$ potentially lead to an enhanced activity of the hypothalamus-pituitary-adrenal (HPA) axis, which can be measured in the cortisol level of the saliva [5]. However, some studies examining cortisol responses to exercise or psychological stress failed to find increased cortisol levels, suggesting that individual difference variables may moderate the link between stress and cortisol response. Although some individual difference variables that moderate the cortisol response have been previously identified in adults [6] research on moderating variables in children and adolescents is still rare. The present study examined the effect of the implicit and explicit power motive on the cortisol response to psychosocial stress and exercise in an adolescent age group.

\section{THE CORTISOL RESPONSE TO EXERCISE AND PSYCHOSOCIAL STRESS IN ADOLESCENTS}

Cortisol response to exercise. Research on the cortisol response to exercise in children and adolescents has

*Address correspondence to this author at the Mirko Wegner, University of Bern, Fabrikstrasse 8, 3012 Bern, Switzerland; Tel: +41 31 631-5669;

Fax:+4131631-4361; E-mail: mirko.wegner@ispw.unibe.ch primarily focused on the consequences for different schoolrelated behavioral functions and for this age group were, for example, conducted by Budde and colleagues $[1,2,7]$. Although for adolescents an acute exercise of $70-85 \%$ of their maximum heart rate $\left(\mathrm{HR}_{\max }\right)$ could be shown to significantly increase participants' cortisol levels $[1,2]$, such increases could not be found after a low-to-moderate intensity exercise $\left(50-65 \%\right.$ of $\left.\mathrm{HR}_{\max }\right)$ of 12 minutes [2]. Acute exercise duration and intensity but also individual difference variables such as physical activity levels could be responsible for these null effects in children and adolescents. Moreover, endurance exercise usually does not include aspects of uncontrollability or social-evaluation [4] that can be found in competitive sports, which have been previously linked to increased cortisol levels.

Cortisol response to psychosocial stress. Besides exercise as physical stress the cortisol-elevating effects of psychosocial stress have also been investigated in children and adolescents [8-11]. Some studies examining winner and loser differences in a contest situation failed to find consistent patterns of cortisol increase after a contest [e.g., 12]. However, these studies were conducted with adults. Several individual difference variables have been suggested to moderate a person's cortisol response to psychosocial stress and thus explain null effects [6]. For children and adolescents, however, only few of these moderating variables like participants' physical activity levels [13], 
depression severity [14], or neuroticism [15] have been previously examined.

\section{THE IMPLICIT POWER MOTIVE AND THE COR- TISOL RESPONSE TO SOCIO-EVALUATIVE SITU- ATIONS}

An individual difference variable potentially responsible for increased activity of the HPA axis in response to socioevaluative situations is the implicit power motive. The implicit power motive is defined as a person's need to have impact on or impress others, and gain reputation and status [16-18]. The implicit power motive represents an affectively toned network of associations that are concerned with having impact on others' feelings, convincing or manipulating them, helping and supporting them, or impressing them and gaining status [18]. The individual is widely unaware of these effects toward power incentives [19]. Given this definition it becomes obvious that an individual high in the power motive will experience more stress if his or her reputation or status is threatened in an uncontrollable, socioevaluative situation [4]. In humans and animals alike the threat of social inferiority and social evaluation lead to higher activation of the HPA axis including elevated cortisol levels [20-22]. Socio-evaluative situations in research in the past were established through, for example, standardized laboratory protocols [22-24], athletic [25] or laboratorybased contests [26]. This research, however, was dominantly conducted with adults while only one study focused on the power motive finding that adults high in the implicit power motive responded with higher cortisol levels if they lost the contest [26].

In addition to this implicit motive system, McClelland and colleagues [27, 28] suggested that an explicit motive system exists that includes self-attributed desires, attitudes, and intentions. Such self-attributes are construed by the individuals' reflections about themselves and their perception of the social environment. Explicit motives are verbally represented, and allow for conscious access but do not possess an affective or hormonal base [29]. For this reason, it has been questioned whether an explicit measure of the power motive could be linked to hormonal activity [30, 31].

The aim of the present research was to examine the effect of a potential individual difference variable that may be responsible for different cortisol responses to typical school stressors. We hypothesized that participants show increased cortisol levels in response to psychosocial stress depending on the strength of their implicit power motive. However, we assumed that a similar response to non-competitive exercise and a control condition in dependence on their implicit power motive cannot be found due to the lack of the characteristics of uncontrollability and social evaluation in both of these groups. We also expected the explicit power motive not to be related to cortisol responses because of its lack of an affective and hormonal base. The present research contributes to the scarce research in children and adolescents [32] identifying an individual difference variable (the implicit power motive) that is important for understanding cortisol responses to psychosocial stress and exercise.

\section{METHODS}

\section{Participants}

Fifty-seven high-school students (33 female) from a school in Berlin, Germany, with a mean age of 14.8 years $(S D=0.5)$ participated in the study. Participants and their parents gave their informed consent to take part in the research procedures. The study was conducted in accordance with the ethical principles of the American Psychological Association (APA) and was approved by the local ethics board. Inclusion criteria for participation in the study were absence of obesity, mental or physical impairments, and current medication according to the students' and parents' self-reports. None of the students taking part in this research had to be excluded on the basis of these criteria. Participants did not receive financial compensation for participation. Findings of this study, but not related to the power motive, were previously reported $[22,33,34]$.

\section{Procedure}

Participants were tested in parallel on the same day. All students completed a questionnaire regarding their implicit (Operant Motive Test) and explicit power motive (Personality Research Form). Subsequently, the first cortisol sample was taken. Participants were required to abstain from eating, drinking, and oral hygiene two hours before the first cortisol sample collection. After the pre-test, participants were randomly assigned to two experimental groups and one control group. In the first experimental group (exercise, $n=$ 17, 9 girls), participants ran 15 minutes at a moderate intensity of $65-75 \%$ of their maximum heart rate $\left(\mathrm{HR}_{\max }\right)$. This intensity has been previously shown to produce significant salivary cortisol increases [35-37]. The $\mathrm{HR}_{\max }$ was determined by means of a Shuttle Run Test [38]. A moderate exercise intensity was chosen because previous studies have shown to positively affect cognitive performance of adolescents, which is of importance in a school setting [2]. A Polar device (HRM RS400, Polar Electro Ltd., Kempele, Finland) was used to monitor participants' heart rates. The second experimental group (psychosocial stress, $n=19,11$ girls) worked on verbal and analytical tasks of a standardized measure of intelligence [39]. The number of tasks chosen for the intelligence test was way beyond feasibility for the students. Participants were told that their intelligence quotients (IQ) would be made public in front of the class immediately after the test session. The intelligence test was used in order to create a situation over which participants had no control and that is socio-evaluative [22]. In the control group $(n=21,11$ girls), students participated in a teacher-centered lesson for 15 minutes. Thirty minutes past the first saliva sample collection a second cortisol sample was collected. Test sessions started in parallel at noon $(1200 \mathrm{~h})$ in order to minimize effects of circadian rhythm. These lasted approximately one hour. All participants were fully debriefed immediately after the tests.

\section{Measures}

Cortisol. Salivary cortisol samples were collected two times, prior and post the stress induction period. Saliva was 
stimulated by chewing a synthetic swab for one minute and collected with Salivettes with a blue cap (Sarstedt, Nümbrecht, Germany). These swabs were placed in a plastic tube and stored at $-20^{\circ} \mathrm{C}$ until analysis. The biochemical analyses took place at the Charite Berlin (Germany). A chemiluminescence immunoassay procedure (IBL, Hamburg, Germany) was performed in order to assess salivary cortisol levels. Intra- and inter-assay coefficients were below $8 \%$. Because of their skewed distribution all cortisol values were log-transformed. The resulting normally distributed variables were used to calculate the change score by regressing the pre-test cortisol levels on the post-test cortisol measure. The residualized change score of cortisol was then entered in the hierarchical regression model.

Power motive. Participants' implicit power motive was assessed using the Operant Motive Test (OMT) [40]. The measure consists of 15 picture cues. For each picture students had to answer four guiding questions using short sentences within 5 minutes of time. The answers were coded for the implicit power motive when participants indicated that a person or group had impact or control over others [16, 40, 41]. These also included actions that imply having impact on others' feelings, persuade, convince, or manipulate others, but also help, educate, and support them. Moreover, acts like impressing others or gain reputation and status were coded as power-motivated [18]. Inter-rater and intra-rater agreement of two trained coders was .87, and .90, respectively. Convergent validity of the power scale of the OMT with the Thematic Apperception Test (TAT) score [42, 43], $r=.47, p<.01$, has been previously reported [44]. The OMT power scale has been shown to be related to managers' leadership skills and decision making [44]. Moreover, the OMT scales have been shown related to different competitive behavior in sports [45-47].

Additionally, students' explicit power motive was assessed using the Personality Research Form (PRF) [48]. The power scale consists of 16 items and is concerned with statements on how much a person strives to have influence on or control over others, and has positive associations with being a leader [48]. An item example for the power scale is "I try to control others rather than permit them to control $m e$ ". Participants have to respond in a dichotomous format whether the statements do ("Right") or do not apply to them ("Wrong"). The internal consistency of the explicit power scale in the present study was .74 .

\section{Design and Data Analysis}

The stressor was varied experimentally with students randomly assigned to the psychosocial, the exercise, and the control group. The indirect (OMT) and direct motive measures (PRF) were used as the quantitative independent variables measuring individual differences in the power motive. The dependent variable was the change in salivary cortisol levels from pre to post stressor.

\section{RESULTS}

\section{Preliminary Analyses}

Exploratory analyses confirmed that participants' gender and age had no significant impact on the results reported below. Additionally, in none of the experimental groups changes in cortisol levels from pre to post test independent of the power motive were found: In the control group, participants showed no significant increase in cortisol from pre $(M=1.43, S D=0.81)$ to post $(M=1.74, S D=0.67)$ test, $t(20)=1.39, p=.178, d=0.42$. In the exercise group, also no significant increase in participants' cortisol levels were found from pre $(M=1.73, S D=0.64)$ to post $(M=1.87, S D$ $=1.40)$ exercise stress, $t(16)=0.32, p=.754, d=0.13$. Finally, in the psychosocial stress group participants showed no increased cortisol levels from pre $(M=1.89, S D=0.86)$ to post $(M=2.40, S D=1.27)$ stress induction, $t(18)=-1.28$, $p=0.216, d=0.47$.

\section{Changes in Cortisol Levels Moderated by the Implicit Power Motive}

To test whether participants differed regarding their cortisol responses to the stressors depending on the strength of their implicit power motives we conducted a hierarchical regression analysis with the residualized change score of cortisol as the dependent variable. We entered the implicit power motive score and the experimental conditions ${ }^{1}$ in the first block of the regression analysis. In the second block we added the interaction terms of the experimental conditions and the power motive score. Only by including the interaction terms for experimental group allocation $\times$ implicit power motive the regression analysis was rendered significant, $R^{2}=.27\left(\Delta R^{2}=.16\right), F(5,52)=3.84, p=.005$.

The implicit power motive, $B=-0.816, S E=0.352, p r=$ $-.31, t=-2.32, p=.024$ and allocation to the psychosocial stress group, $B=0.615, S E=0.284, p r=.291, t=2.17, p=$ .035 , significantly affected participants' cortisol changes. Additionally, the interaction of the implicit power motive and the psychosocial stress group allocation showed a significant effect in the second step of the hierarchical regression analysis, $B=0.940, S E=0.287, p r=.417, t=$ $3.28, p=.002$.

Follow-up analyses on the interaction terms of implicit power motive $\times$ experimental group documented that participants' changes in cortisol levels in the psychosocial stress group were positively associated with the implicit power motive, $B=0.627, S E=0.194, p r=.62, t=3.23, p=$ .005. Participants high in the power motive responded with higher increases in cortisol levels to psychosocial stress. In the exercise group the power motive was also positively but not significantly related to cortisol changes, $B=0.294$, $S E=$ $0.285, p r=.26, t=1.03, p=.318$. By contrast, in the control group the association between the implicit power motive and post-stressor cortisol was negative, $B=-0.314, S E=0.153$, $p r=-.43, t=-2.05, p=.054$. For illustration of the interaction pattern see Fig. (1).

\section{Changes in Cortisol Levels Moderated by the Explicit Power Motive}

The explicit power motive was not directly related to the change in salivary cortisol levels (main effect). The explicit power motive also did not moderate the cortisol response to

\footnotetext{
${ }^{1}$ The experimental conditions were dummy-coded.
} 


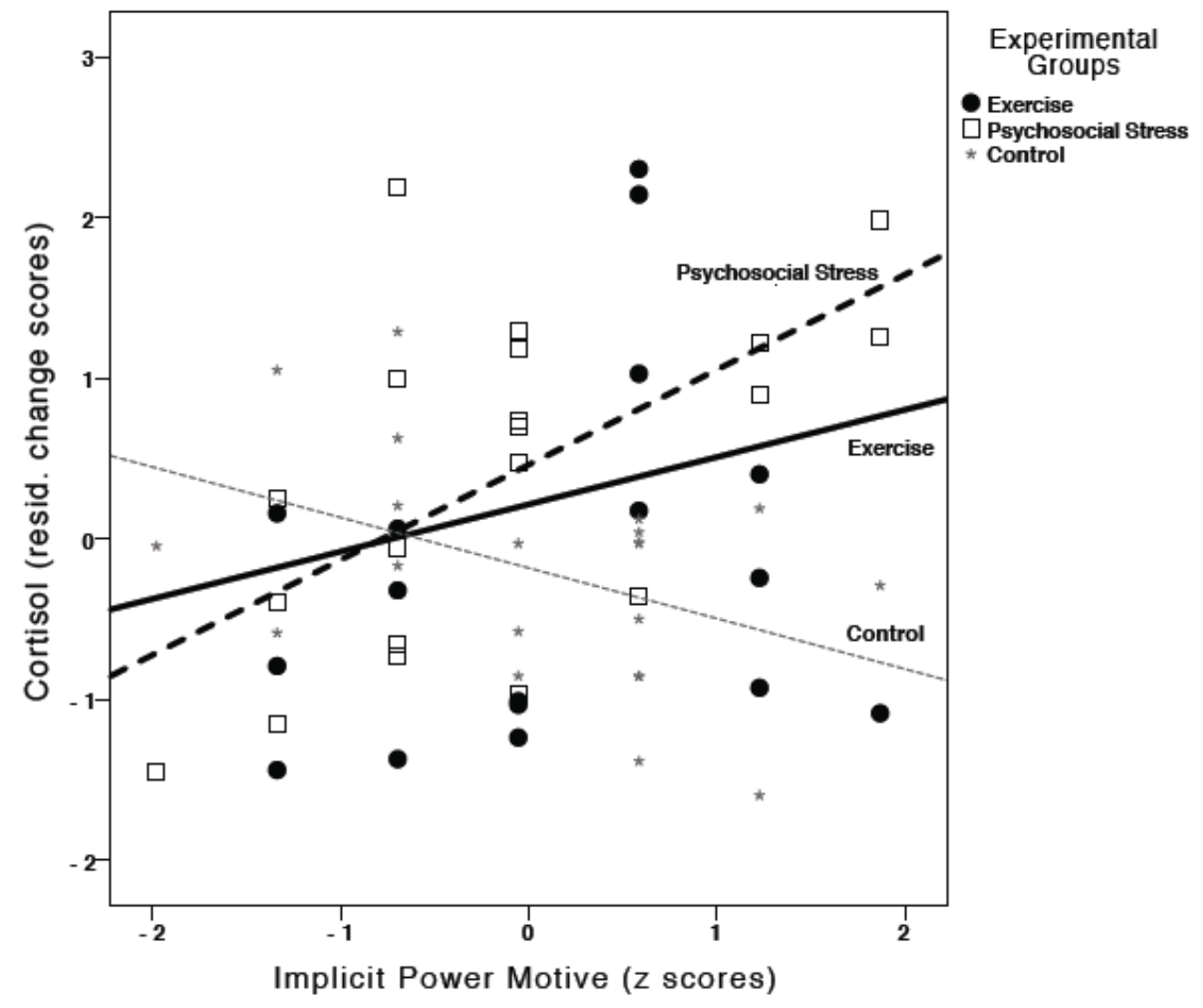

Fig. (1). Association between the implicit power motive ( $n$ Pow) and pre-post-stressor salivary cortisol changes (log-transformed) in the three experimental groups.

the different stressors (interaction effect) used in the present study.

\section{DISCUSSION}

In the present study, we investigated how the power motive as an individual difference variable moderates cortisol stress responses to psychosocial stress and exercise. This was done employing a sample of adolescents in a school setting. It is the first time that an experimental study tested cortisol responses to psychosocial and acute physiological (exercise) stressors in an adolescent sample. Our main finding, supporting our hypothesis, is that salivary cortisol increases in response to psychosocial stress are significantly dependent on the strength of participants' implicit power motives.

The implicit power motive has previously been linked to dominance behavior and cortisol activity in humans [27, 49, 50]. Only one study with adults previously proposed that stress responses are higher in individuals with a higher implicit power motive; and thus are more susceptible to social comparison and competition [26]. In that study, higher cortisol levels were found in losers of a competition with a high implicit power motive, reflecting higher stress levels resulting from loss of status. Individual differences regarding the implicit power motive seem to be of importance because some studies that investigated only contest outcomes did not find different cortisol responses of winners vs losers [51]. This was also the case in the present study. In our adolescent sample we were able to replicate the Wirth et al. [26] findings independent of the outcome of the psychosocial stressor. In the school setting we used, participants with a high implicit power motive showed significantly increased salivary cortisol responses to a psychosocial stressor that only announced social evaluation. This pattern of results can be expected in situations that are unpredictable, uncontrollable, and socio-evaluative for the participants [4, 22]. In our study, the results were additionally independent of the actual outcome of the test situation, meaning students did not know whether they performed well or badly in the test. Individuals, who have a high need for control over themselves and others as well as for personal status and reputation (high implicit power motive) [16, 17] may especially experience stress in such situations. Our students assumed that their results of the intelligence test would be published in front of the class right after testing. This was done in order to induce a situation of social comparison. Such social contests, in which a person's status is at stake (socio-evaluative aspect), were shown to lead to activation of the HPA axis [4, 22]. In competitive situations, individuals with a high concern for status and dominance behavior respond with higher cortisol levels when their status is threatened (e.g., by losing a competition) [52].

We were also interested in whether these power motivedependent cortisol responses to psychosocial stress are different from the cortisol responses to exercise. In the present sample, the salivary cortisol responses to physical stress should be evoked by 15 minutes of exercise at a moderate $\left(65-75 \%\right.$ of $\left.\mathrm{HR}_{\max }\right)$ intensity. Although the implicit power motive was also positively associated with cortisol levels in response to this kind of exercise this finding was not significant. This is in accordance with our hypotheses 
because pure exercise without competition is usually not related to social threats.

The current research is also subject to limitations. In the present study we only collected two salivary cortisol samples. This procedure took place before and after exposure to two different kinds of stressors. Other researchers performed up to ten saliva samples when analyzing the cortisol response pattern $[5,53]$. The post-test in the present study was performed 30 minutes past the onset of the stressors. From the elaborated studies by Kirschbaum and colleagues [5] on the cortisol kinetics we concluded that 30 minutes would represent an optimal point-of-time to measure cortisol responses to the stressors. Moreover, the effect of the power motive on cortisol responses in the control condition was close to significance level. This finding was unexpected. However, it might be speculated that in the control group participants with a high implicit power motive may have felt under-aroused. In the control condition, participants took part in a teacher-centered lesson for 15 minutes without being able to talk. For a person whose need for social efficacy is high (high implicit power motive) such condition might lead to less involvement and arousal resulting in lower cortisol levels.

From the present research it can also be reasoned that the strength of the individual's cortisol response is dependent on individual difference factors like the implicit power motive. Thus, in a test situation at school in which psychosocial stress is induced children with high implicit power motives may benefit depending on the strength of the stress induction and the skill needed in the test situation. To what extent these variables affect behavioral parameters can only be obtained with these factors measured simultaneously in future studies.

\section{LIST OF ABBREVIATIONS}

$$
\begin{array}{ll}
\mathrm{h} & =\text { Hours } \\
\text { HPA axis } & =\text { Hypothalamus-Pituitary-Adrenal Axis } \\
\text { HRM } & =\text { Heart Rate Monitor } \\
\text { HR }_{\max } & =\text { Maximum Heart Rate } \\
\text { IQ } & =\text { Intelligence Quotient } \\
\text { min } & =\text { Minutes } \\
\text { OMT } & =\text { Operant Motive Test } \\
\text { PRF } & =\text { Personality Research Form } \\
\text { TAT } & =\text { Thematic Apperception Test }
\end{array}
$$

\section{CONFLICT OF INTEREST}

The authors confirm that this article content has no conflict of interest.

\section{ACKNOWLEDGEMENTS}

This work was supported by funds from the Reykjavik University, Iceland, which had no further role in the study design; collection, analysis, and interpretation of data; in writing of the report; or in the decision to submit the paper for publication.
Henning Budde was supported by a funding from the Reykjavik University and is further supported by the German Research Foundation (DFG, Deutsche Forschungsgemeinschaft); BU 1837/5-1.

\section{REFERENCES}

[1] Budde H, Pietrassyk-Kendziorra S, Bohm S, Voelcker-Rehage C. Hormonal responses to physical and cognitive stress in a school setting. Neurosci Lett 2010; 474(3): 131-4.

[2] Budde H, Voelcker-Rehage C, Pietrassyk-Kendziorra S, Machado S, Ribeiro P, Arafat AM. Steroid hormones in the saliva of adolescents after different exercise intensities and their influence on working memory in a school setting. Psychoneuroendocrinology 2010; 35(3): 382-91.

[3] Kirschbaum C, Hellhammer DH. Salivary cortisol in psychobiological research: An overview. Neuropsychobiology 1989; 22: 15069.

[4] Dickerson SS, Kemeny ME. Acute stressors and cortisol responses: A theoretical integration and synthesis of laboratory research. Psychol Bull 2004; 130(3): 355-91.

[5] Kirschbaum C, Hellhammer DH. Salivary cortisol in psychoneuroendocrine research: Recent developments and applications. Psychoneuroendocrinology 1994; 19(4): 313-33.

[6] Kudielka BM, Hellhammer DH, Wüst S. Why do we respond so differently? Reviewing determinants of human salivary cortisol responses to challenge. Psychoneuroendocrinology 2009; 34(1): 218 .

[7] Budde H, Windisch C, Kudielka BM, Voelcker-Rehage C. Saliva cortisol in school children after acute physical exercise. Neurosci Lett 2010; 483(1): 16-9.

[8] Buske-Kirschbaum A, Jobst S, Wustmans A, Kirschbaum C, Rauh W, Hellhammer DH. Attenuated free cortisol response to psychosocial stress in children with atopic dermatitis. Psychosom Med 1997; 59(4): 419-26.

[9] Kirschbaum C, Hellhammer DH, Strasburger CJ, Tiling E, Kamp R, Lüddecke H. Relationships between salivary cortisol, electrodermal activity, and anxiety under mild experimental stress in children. In: Weiner H, Florin I, Murison R, Hellhammer D, Eds. Frontiers of stress research. Toronto: Hans Huber Publishers; 1989.

[10] Buske-Kirschbaum A, von Auer K, Krieger S, Weis S, Rauh W, Hellhammer DH. Blunted cortisol responses to psychosocial stress in asthmatic children: A general feature of atopic disease? Psychosom Med 2003; 65: 806-10.

[11] Gunnar MR, Wewerka S, Frenn K, Long JD, Griggs C. Developmental changes in hypothalamus-pituitary-adrenal activity over the transition to adolescence: Normative changes and associations with puberty. Dev Psychopathol 2009; 21(1): 69-85.

[12] Booth A, Shelley G, Mazur A, Tharp G, Kittok R. Testosterone, and winning and losing in human competition. Horm Behav 1989; 23(4): 556-71

[13] Martikainen S, Pesonen A-K, Lahti J, Heinonen K, et al. Higher levels of physical activity are associated with lower hypothalamicpituitary-adrenocortical axis reactivity to psychosocial stress in children. J Clin Endocrin Metab 2013; 98(4): E619-27.

[14] Harkness KL, Stewart JG, Wynne-Edwards KE. Cortisol reactivity to social stress in adolescents: Role of depression severity and child maltreatment. Psychoneuroendocrinology 2011; 36: 173-81.

[15] Hauner KKY, Adam EK, Mineka S, et al. Neuroticism and introversion are associated with salivary cortisol patterns in adolescents. Psychoneuroendocrinology 2008; 33: 1344-56.

[16] Winter DG. The power motive. New York: The Free Press; 1973.

[17] McClelland DC. Power: The inner experience. New York: Irvington Publishers; 1975.

[18] Winter DG. Manual for scoring motive imagery in running text (Version 4.2): University of Michigan; 1994.

[19] McClelland DC. Biological aspects of human motivation. In: Halisch F, Kuhl J, editors. Motivation, intention, and volition. Berlin: Springer; 1987. p. 11-9.

[20] Li L, Power C, Kelly S, Kirschbaum C, Hertzman C. Life-time socio-economic position and cortisol patterns in mid-life. Psychoneuroendocrinology 2007; 32: 824-33.

[21] Cohen S, Schwartz JE, Epel E, Kirschbaum C, Sidney S, Seeman T. Socioeconomic status, race, and diurnal cortisol decline in the 
Coronary Artery Risk Development in Young Adults (CARDIA) study. Psychosom Med 2006; 68: 41-50.

[22] Wegner M, Müller-Alcazar A, Jäger A, Machado S, Arias-Carrión $\mathrm{O}$, Budde H. Psychosocial stress but not exercise increases cortisol and reduces state anxiety levels in school classes - Results from a stressor applicable in large group settings. CNS Neurol Disord Drug Targets 2014; 13(6): 1015-20.

[23] Kudielka BM, Hellhammer DH, Kirschbaum C, Harmon-Jones E, Winkielman P. Ten years of research with the Trier Social Stress Test-Revisited. In: Harmon-Jones E, Winkielman P, Eds. Social neuroscience: Integrating biological and psychological explanations of social behavior. New York: Guilford Press; 2007. p. 56-83.

[24] Kirschbaum C, Pirke K-M, Hellhammer DH. The "Trier Social Stress Test" - A tool for investigating psychobiological stress responses in a laboratory setting. Neuropsychobiology 1993; 28 : 76-81.

[25] Gonzalez-Bono E, Salvador A, Serrano MA, Ricarte J. Testosterone, cortisol, and mood in a sports team competition. Horm Behav 1999; 35(1): 55-62.

[26] Wirth MM, Welsh KM, Schultheiss OC. Salivary cortisol changes in humans after winning or losing a dominance contest depend on implicit power motivation. Horm Behav 2006; 49(3): 346-52.

[27] McClelland DC, Koestner R, Weinberger J. How do self-attributed and implicit motives differ? Psychol Rev 1989; 96(4): 690-702.

[28] Weinberger J, McClelland DC. Cognitive versus traditional motivational models: Irreconcilable or complementary? In: Higgins ET, Sorrentino RM, Eds. Handbook of motivation and cognition: foundations of social behavior. New York: Guilford; 1990; p. 56297.

[29] Schultheiss OC. Implicit motives. In: John OP, Robins RW, Pervin LA, editors. Handbook of personality: Theory and research. 3rd ed. New York: Guilford Press; 2008. p. 603-33.

[30] Archer J. The influence of testosterone on human aggression. Br J Psychol 1991; 82: 1-28.

[31] Mazur A, Booth A. Testosterone and dominance in men. Behav Brain Sci 1998; 21(3): 353-97.

[32] Wegner M, Windisch C, Budde H. The psychological effects of acute physical stress in the school context: An overview. Z Sport Psychol 2012; 19(1): 37-47.

[33] Wegner M, Koedijker JM, Budde H. The effect of acute exercise and psychosocial stress on fine motor skills and testosterone concentration in the saliva of high school students. PLoS One 2014; 9(3): e92953.

[34] Wegner M, Schüler J, Budde H. The implicit affiliation motive moderates cortisol responses to acute psychosocial stress in high school students. Psychoneuroendocrinology 2014; 48: 162-8.

[35] Brownlee KK, Moore AW, Hackney AC. Relationship between circulating cortisol and testosterone: Influence of physical exercise. J Sports Sci Med. 2005; 4: 76-83.

[36] Gatti R, De Palo EF. An update: Salivary hormones and physical exercise. Scand J Med Sci Sports. 2011; 21(2): 157-69.
[37] Hill EE, Zack E, Battaglini C, Viru M, Viru A, Hackney AC. Exercise and circulating cortisol levels: The intensity threshold effect. J Endocrinol Invest 2008; 31(7): 587-91.

[38] Leger L, Gadoury C. Validity of the $20 \mathrm{~m}$ shuttle run test with 1 min stages to predict VO2max in adults. Can J Sport Sci 1989; 14(1): 21-6.

[39] Petermann F, Petermann U. Hamburg-Wechsler-Intelligenztest für Kinder (HAWIK-IV) [Hamburg-Wechsel-Intelligence Test for children (HAWIK-IV)]. Bern: Huber; 2006.

[40] Kuhl J, Scheffer D. Der Operante Multi-Motiv-Test (OMT): Manual [The Operant Multimotive Test (OMT): Manual]. Osnabrück, Germany: University of Osnabrück; 1999.

[41] McClelland DC. Human motivation. Glenview: Scott, Foresman \& Co.; 1985.

[42] Morgan C, Murray HA. A method for investigating fantasies: The Thematic Apperception Test. Arch Neurol Psychiatry 1935; 34 289-306.

[43] Schultheiss OC, Pang JS. Measuring implicit motives. In: Robin RW, Fraley RC, Krueger R, Eds. Handbook of research methods in personality psychology. New York: Guilford; 2007; p. 322-44.

[44] Scheffer D, Kuhl J, Eichstaedt J. The Operant Motive Test (OMT): contents, scoring, psychometric values, and validation. In: Stiensmeier-Pelster J, Rheinberg F, Eds. Diagnostic of motivation and self-concept. Göttingen, Germany: Hogrefe; 2003; pp. 151-80.

[45] Wegner M, Bohnacker V, Mempel G, Teubel T, Schüler J. Explicit and implicit affiliation motives predict verbal and nonverbal social behavior in sports competition. Psychol Sport Exerc 2014; 15: 58895.

[46] Wegner M, Teubel T. The implicit achievement motive predicts match performances and the explicit motive predicts choices for target distances in team sports. Int J Sport Psychol 2014; 45(6) 621-38.

[47] Gröpel P, Schöne L, Wegner M. Elite and recreational athletes' implicit and explicit motives. Z Sport Psychol 2015; 22(1): 6-19.

[48] Jackson DN. Personality Research Form manual. 3rd ed. New York: Research Psychologists Press; 1999.

[49] McClelland DC, Burnham DH. Power is the great motivator. Harvard Bus Rev 1976; 54(2): 100-10.

[50] Schultheiss OC, Campbell KL, McClelland DC. Implicit power motivation moderates men's testosterone responses to imagined and real dominance success. Horm Behav 1999; 36(3): 234-41.

[51] Fry AC, Schilling BK, Fleck SJ, Kraemer WJ. Relationships between competitive wrestling success and neuroendocrine responses. J Strength Cond Res 2011; 25(1): 40-5.

[52] Mehta PH, Jones AC, Josephs RA. The social endocrinology of dominance: Basal testosterone predicts cortisol changes and behavior following victory and defeat. J Pers Soc Psychol 2008; 94(6): 1078-93.

[53] von Dawans B, Kirschbaum C, Heinrichs M. The Trier Social Stress Test for Groups (TSST-G): A new research tool for controlled simultaneous social stress exposure in a group format. Psychoneuroendocrinology 2011; 36: 514-22. 